\title{
A simple field method to measure the hydrodynamic properties of soil surface crust
}

\author{
Vincenzo Alagna, Vincenzo Bagarello, Simone Di Prima, Giuseppe Giordano, \\ Massimo lovino \\ Dipartimento di Scienze Agrarie e Forestali, Università degli Studi di Palermo, Italy
}

\begin{abstract}
The hydraulic resistance of the surface crust was determined by a combination of two infiltrometric techniques: first, a surface measurement of steady-state infiltration rate is conducted by a mini-disk tension infiltrometer (MDI); then, the surface crust is removed, its thickness is measured, and a ponded infiltration test is performed at the same site. The Beerkan Estimation of Soil Transfer parameters (BEST) method is applied to estimate the hydraulic properties of the underlying soil provided the particlesize distribution and the bulk density are known. Under the assumption of a unit gradient of hydraulic head below the soil crust, the pressure head at the interface crust-soil is derived. Finally, the hydraulic conductivity of the crust is calculated from the steady-state water flow measured by the MDI and the Darcy law. The method was tested in a sandy loam and a clay soil. In the sandy loam soil, a 2-3 mm thick slaking crust was visually observed, but no increased surface hydraulic resistance was detected in 10 out of 11 cases. In the clay soil, a 5-7 mm thick crust was formed by gradual coalescence of the plastic, wet aggregates by rainfall compaction. In 10 out of 15 tests, the steady-state infiltration rate with the crust was lower than the underlying soil saturated hydraulic conductivity, denoting an increased hydraulic resistance of the surface crust. For the clay soil, the mean value of the hydraulic resistance was practically independent of the crust thickness and varied between 78 and $81 \mathrm{~min}$.
\end{abstract}

Correspondence: Massimo Iovino, Dipartimento di Scienze Agrarie e Forestali, Università degli Studi di Palermo, viale delle Scienze, ed. 4, ingr. E, 90128 Palermo, Italy.

Tel. +39.091 .23897070 - Fax +39.091 .484035 .

E-mail:massimo.iovino@unipa.it

Key words: soil surface crust, mini disk tension infiltrometer, BEST procedure.

Acknowledgements: the authors would like to thank Giuseppe Nicolosi for his help in the experimental work.

Contributions: theory was developed by V. Bagarello and M. Iovino. All authors analyzed the data and contributed to write the manuscript.

Funding: the study was supported by grants of the Sicilian Region (Progetto Tristezza).

Conference presentation: this paper was presented at 10th AIIA Conference: "AIIA13 - Horizons in agricultural, forestry and biosystems engineering", Viterbo, Italy, September 8-12, 2013.

(C) Copyright V. Alagna et al., 2013

Licensee PAGEPress, Italy

Journal of Agricultural Engineering 2013; XLIV(s2):e14

doi:10.4081/jae.2013.s2.e14

\section{Introduction}

In many arid and semi-arid regions, the combination of high intensity rainfall and unstable soil aggregation frequently leads to the development of a surface crust characterized by higher bulk density and lower porosity than the underlying soil. It acts as a barrier to water infiltration, hampers germination of seeds and reduces root aeration and water availability. Preventing these problems requires an understanding and prediction of how soil degradation develops in the field (Bresson and Boiffin, 1990). In the formation of surface crusts, aggregate stability plays a key role. Rainfall or irrigation water may destroy soil aggregates by two processes. First, breakdown of aggregates as consequence of slaking when immersed in water. Second, mechanical destruction of aggregates as consequence of water drop impacts (De Jong et al., 2011). In both cases, the loose particles are partially moved by splash erosion and carried into the soil mass by the infiltrating water where they fill the voids between the aggregates. Valentin and Bresson (1992) referred to this as structural crust. Fine particles, resulting from aggregates breakdown, can be translocated to a certain distance from their original location. After the rainstorm, a depositional crust of variable thickness can be deposited on the soil surface, mainly consisting of clay that was in suspension during rainstorms. A detailed classification of structural and depositional crusts was proposed by Valentin and Bresson (1992).

Investigations on the effects of surface crusting on infiltration rate were conducted since the middle of the $20^{\text {th }}$ century. A review of laboratory and field studies aimed at investigating the factors involved in rainfall-induced seal formation and improving the knowledge about soil crusting effects can be found in Assouline (2004). A simple approach to model the effect of surface sealing on infiltration consists of considering a well established saturated crust with constant thickness and saturated conductivity. Hillel and Gardner (1969) accounted for the crust effect through the hydraulic resistance which is the ratio between the crust thickness and the corresponding conductivity. Under ponded condition, if the crust is less pervious than the lower layer, a negative pressure head can develop in the subsoil (Hillel and Gardner, 1969). A measurement of the pressure head at the crust-soil interface can be obtained by minitensiomenter horizontally inserted beneath the soil crust.

Vandervaere et al. (1997) proposed a method which uses tension disk infiltration data at several water supply potential, together with information from pre-installed minitensiometer below the soil crust to estimate hydraulic conductivity, matric flux potential and sorptivity. An alternative approach involves the use of the inverse solution and two transient infiltration experiments conducted in the same site by a disk infiltrometer before and after the removal of the soil crust (Šimůnek et al, 1998). However, tensiometers insertion may be problematic in situ whereas the inverse modeling raises problems of non-uniqueness of the solution (Šimůnek and van Genuchten, 1997). Touma et al. (2011) proposed a method to determine the surface crust resistance 
that combines two types of in situ experiments: i) a rain simulation experiment, and ii) a single ring infiltration test on the same soil after removal of the crust. Steady state infiltration rate through the crust is calculated as the difference between the runoff rate and the applied rainfall intensity. The subsoil hydraulic properties are determined by the combination of pedotransfer functions and a transient model for 3D infiltration in a homogeneous, uniformly unsaturated soil. The method appeared reliable even if it was applied to only one soil type and texture. However, the field use of the rainfall simulator is complicated and the spatial support for the proposed method is questionable. In fact, the two experiments do not sample the same area $\left(1 \mathrm{~m}^{2}\right.$, or more, for the simulated rainfall against $<0.02 \mathrm{~m}^{2}$ for ring test).

An alternative to the rainfall simulator for measuring the steady state infiltration rate through the soil crust could be the use of the minidisk tension infiltrometer (MDI) that requires a small amount of water and it is easily transportable in the field (Lichner et al., 2007; Madsen and Chandler, 2007; Dohnal et al., 2010). A laboratory application of the MDI to measure the infiltration rates of badlands crust was conducted by Li et al. (2005). The MDI samples a limited area (approximately $15 \mathrm{~cm}^{2}$ ) with a very limited disturbance of soil surface. This small sampled area implies that local crust characteristics, including thickness, can be precisely determined. The minimization of disturbance is a great advantage for the characterization of the soil surface crust in the field given the nature of the thin sealing layer, that can easily be disrupted under minimal mechanical action.

The purpose of this investigation was to develop and test a simplified method to determine the hydrodinamic properties of the surface crust. Following the approach by Touma et al. (2011), the hydraulic resistance of the crust is determined by a combination of two infiltrometric techniques: first, a surface measurement of steady-state infiltration rate is conducted by a MDI; then, the surface crust is removed, its thickness is measured, and a ponded infiltration test is performed at the same site. The Beerkan Estimation of Soil Transfer parameters (BEST) procedure (Lassabatère et al., 2006) is applied to estimate the hydraulic properties of the underlying soil provided the particle-size distribution and the bulk density are known. The method was tested in a sandy loam and a clay soil exhibiting a structural crust that developed due to the autumn-winter rainstorms typically occurring under Mediterranean climate.

\section{Theory}

The method is based on the earlier work by Hillel and Gardner (1969). The flux across a surface crust of thickness $L_{c}(\mathrm{~L})$ is given by:

$$
q_{c}=-K_{c} \frac{h_{s}-L_{c}-h_{0}}{L_{c}}
$$

in which $h_{0}(\mathrm{~L})$ is the water pressure head at the crust surface, $h_{s}(\mathrm{~L})$ is the pressure head at the soil-crust interface and $K_{c}\left(\mathrm{~L} \mathrm{~T}^{-1}\right)$ is the hydraulic conductivity of the soil crust. For zero ponded conditions, $h_{0}$ becomes zero; furthermore, the thickness of the crust (of the order of a few $\mathrm{mm}$ ) can be neglected in the numerator of eq. (1) which becomes:

$$
q_{c}=-K_{c} \frac{h_{s}}{L_{c}}=-\frac{h_{s}}{R_{c}}
$$

where $R_{\mathrm{c}}(\mathrm{T})$ is the crust resistance. For a transient infiltration process, $h_{s}$ increases with time up to a constant value when steady state condition is reached. Then, the water flux entering the subsoil, $q_{s}\left(\mathrm{~L} \mathrm{~T}^{-1}\right)$, can be calculated by the Darcy law:

$$
q_{s}=-K\left(h_{s}\right)\left(\frac{d h}{d z}-1\right)
$$

where $K\left(h_{s}\right)$ is the unsaturated hydraulic conductivity of the subsoil corresponding to a pressure head $h_{s}$ and $(\mathrm{d} h / \mathrm{d} z-1)$ is the hydraulic gradient at soil-crust interface. Due to the continuity of the flux at the soilcrust interface, $q_{c}=q_{s}$. Furthermore, when steady state is reached, $\mathrm{d} h / \mathrm{d} z$ tends to become a negligible quantity and eq. (3) reduces to:

$$
q_{s}=K\left(h_{s}\right)
$$

Combining eqs. (2) and (4), the following equation for the crust hydraulic resistance is obtained:

$$
R_{c}=-\frac{h_{s}}{K\left(h_{s}\right)}
$$

When the crust thickness cannot be neglected in the numerator of eq. (1), the crust resistance will be given by:

$$
R_{c}=-\frac{h_{s}-L_{c}}{K\left(h_{s}\right)}
$$

Therefore, determination of the soil crust resistance needs the knowledge of the soil hydraulic properties of the subsoil, $\theta(h)$ e $K(h)$, and execution of an infiltration test in which water is supplied at the upper surface of the soil crust under zero ponded conditions. Under steady state conditions, the unsaturated hydraulic conductivity of the subsoil $K\left(h_{s}\right)$ is determined by eq. (4) and, then, the pressure head at the crust-subsoil interface is derived by inverting the $K(h)$ relationship. Crust hydraulic resistance is finally obtained by eqs. (5) or (6).

The hydraulic properties of the subsoil can be determined by the BEST method (Lassabatère et al., 2006) that focuses specifically on the van Genuchten (1980) relationship for the water retention curve with the Burdine (1953) condition and the Brooks and Corey (1964) relationship for hydraulic conductivity:

$$
\begin{aligned}
& \frac{\theta-\theta_{r}}{\theta_{f s}-\theta_{r}}=\left[1+\left(\frac{h}{h_{g}}\right)^{n}\right]^{-m} \\
& m=1-\frac{2}{n} \\
& \frac{K(\theta)}{K_{f s}}=\left(\frac{\theta-\theta_{r}}{\theta_{f s}-\theta_{r}}\right)^{\eta} \\
& \eta=\frac{2}{m \times n}+3
\end{aligned}
$$

where $\theta\left(\mathrm{L}^{3} \mathrm{~L}^{-3}\right)$ is the volumetric soil water content, $h(\mathrm{~L})$ is the soil water pressure head, $K\left(\mathrm{~L} \mathrm{~T}^{-1}\right)$ is the soil hydraulic conductivity, $n, m$ and $\eta$ are shape parameters, and $h_{g}(\mathrm{~L}), \theta_{f s}\left(\mathrm{~L}^{3} \mathrm{~L}^{-3}\right.$, field saturated soil water content), $\theta_{r}\left(\mathrm{~L}^{3} \mathrm{~L}^{-3}\right.$, residual soil water content) and $K_{f s}\left(\mathrm{~L} \mathrm{~T}^{-1}\right.$, field saturated soil hydraulic conductivity) are scale parameters. In the BEST procedure, $\theta_{r}$ is assumed to be zero. 
Estimation of the shape parameters is based on the soil particle size distribution (PSD), whereas the scale parameter are estimated by means of an inverse analysis of infiltration data. Cumulative infiltration data, $I(\mathrm{~L})$, are fitted to the analytical formulation derived by Haverkamp et al. (1994) for a transient zero ponded infiltration from a circular surface:

$$
I(t)=S \sqrt{t}+\left(A S^{2}+B K_{f s}\right) t
$$

where $t(\mathrm{~T})$ is the time, $S\left(\mathrm{~L} \mathrm{~T}^{-1 / 2}\right)$ is soil sorptivity, and $A\left(\mathrm{~L}^{-1}\right)$ and $B$ are constants that depend on the shape parameter $\eta$, the scale parameter $\theta_{f s}$, the ring radius, $r(\mathrm{~L})$, and the initial water content, $\theta_{0}\left(\mathrm{~L}^{3} \mathrm{~L}^{-3}\right)$. The initial and field saturated water contents are measured at the beginning and the end of the infiltration experiment, respectively. BEST first estimates sorptivity by eq.(9) with $K_{f s}$ replaced by its sorptivity function and the experimental steady state infiltration rate, $i_{s}\left(\mathrm{~L} \mathrm{~T}^{-}\right.$ 1):

$$
K_{f s}=i_{s}-A S^{2}
$$

Once sorptivity is estimated, $K_{f s}$ is driven through eq.(10), assuming that steady state has been reached. As eq.(9) is valid only at transient state, the considered duration of the experiment has to be lower than a maximum time, $t_{\max }(\mathrm{T})$ :

$$
t_{\max }=\frac{1}{4(1-B)^{2}}\left(\frac{S}{K_{f s}}\right)^{2}
$$

The pressure head scale parameter, $h_{g}$, is finally estimated by the following relationship (Lassabatere et al., 2010):

$$
h_{g}=-\frac{S^{2}}{c_{p} K_{f s}\left(\theta_{f s}-\theta_{0}\right)\left[1-\left(\frac{\theta_{0}}{\theta_{f s}}\right)^{\eta}\right]}
$$

in which $c_{p}$ is a texture parameter that can be derived from the shape parameters ( $m, n$ and $\eta)$.

\section{Materials and methods}

Validation of the proposed method was performed in two differently textured soils. The first experimental site (Site 1) is located near the Agricultural Faculty of the University of Palermo (UTM: 355500E, $4218950 \mathrm{~N}$ ) in a citrus orchard having a canopy that covers almost completely the soil surface. The soil had received no tillage in the last three years and, in late autumn when the experiments were conducted, uncontrolled weeds covered diffusely but not uniformly the soil surface. According to the USDA classification, the soil is sandy loam with percentages of clay, $c l=15.6 \%$ silt, $s i=27.4 \%$ and sand, $s a=50.7 \%$. Hydraulic resistance of the surface crust was measured at 11 randomly selected points in which a surface crust was visually observed. Site 2 is located in a vineyard near Marsala, western Sicily (UTM: 286250E, $4187250 \mathrm{~N})$. The soil is classified as clay $(c l=54.3 \%, s i=29.2 \%, s a=$
$16.5 \%)$. In late spring, after the winter rainfalls, 15 measurement points were randomly selected approximately in the middle of the crop rows (spaced $2.50 \mathrm{~m}$ ) where soil was not covered by vegetation.

Measurement of the hydraulic resistance of the crust involved a two step experiment (Figure 1). First, the MDI was applied on the surface of the crust to measure the steady state infiltration rate, $q_{c}$. The original MDI device (Decagon Devices, Inc., Pullman, WA) with a disk diameter of $3.2 \mathrm{~cm}$ was used. The pressure head at the soil surface can be regulated from -0.5 to $-7 \mathrm{~cm}$ by a suction control tube at the top of the infiltrometer. A very thin layer of contact material (Spheriglass no.2227, Potter Industries, LaPraire, Canada) was spread on the surface crust to level small irregularities and assure a good hydraulic contact between the porous disk and the soil. Then the MDI was accurately placed on the surface to avoid any disturbance of the crust and the air tube open to start infiltration. The instrument was assured to a rod to keep it in vertical position and to avoid loss of contact with the crust surface during infiltration (Figure 1). The imposed pressure head at the base of the device was not set to zero, as established by theory, but a small suction (approximately $5 \mathrm{~mm}$ ) was applied to consider the thickness of the contact material layer and also to avoid lateral leakage when water is applied onto an unconfined surface at zero (or positive) pressure head. According to Reynolds (2006), the imposed pressure head on the soil surface is higher than the one established at the base of the device by a quantity depending on the thickness of the contact

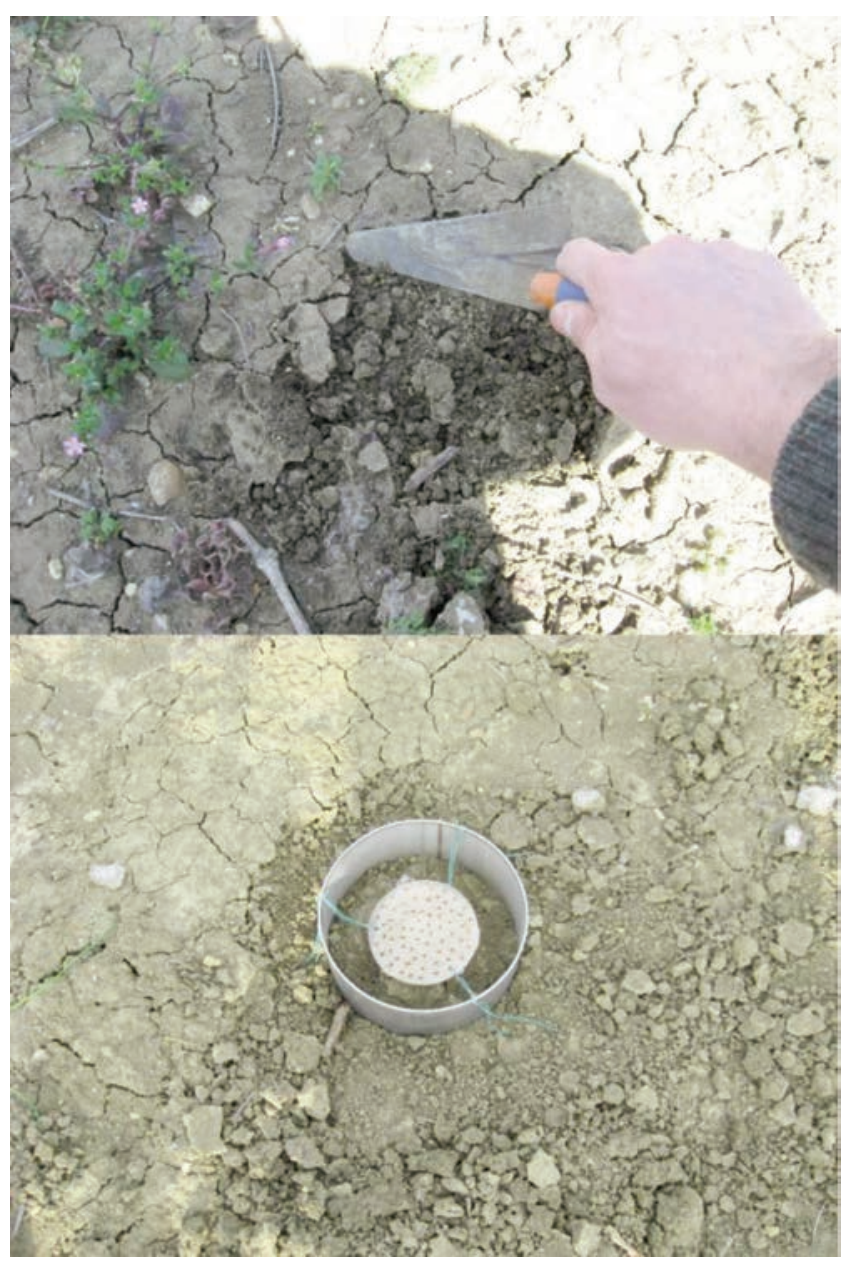

Figure 1. Experimental procedure for determining the hydraulic resistance of the surface soil crust: a) surface crust; b) MDI experiment; c) crust removal; d) ring infiltration test. 
material (i.e., established $h_{0}$ value $>5 \mathrm{~mm}$ ). In addition, considering the low porosity of the sealed surface soil, the use of a slightly negative pressure head at the soil surface should not influence the measurement of the hydraulic resistance of the crust. Visual readings of the water level in the MDI supply tube were taken at $30 \mathrm{~s}$ interval until the complete empting of the reservoir that occurred in approximately $8 \mathrm{~min}$ in the sandy loam soil and $15 \mathrm{~min}$ in the clay soil. Apparent steady-state infiltration rate was deduced from the slope of the linear portion of the cumulative infiltration vs. time plot.

Three days after the MDI measurement, the surface crust was accurately removed and its thickness measured by a gauge. The average of 5-6 measurements was assumed as thickness of the crust at a given measurement point. A ring with an inner diameter of $80 \mathrm{~mm}$ was inserted into the subsoil to a depth of about $10 \mathrm{~mm}$ to avoid lateral loss of the ponded water. A known volume of water $(50 \mathrm{~mL})$ was poured in the cylinder at the start of the measurement and the elapsed time during the infiltration was measured. When the amount of water had completely infiltrated, an identical amount of water was poured into the cylinder, and the time needed for the water to infiltrate was logged. The procedure was repeated until the difference in infiltration time between three consecutive trials became negligible, signaling a practically steady-state infiltration. To avoid disturbance of the soil surface, the water energy was dissipated against a shield placed 10-20 mm above the soil surface (Figure 1). The number of collected $(t, I)$ data points varied with the run between 10 and 16 .

Before conducting the experiment, a disturbed soil sample was collected to estimate the initial gravimetric water content and to determine the PSD, using conventional methods following $\mathrm{H}_{2} \mathrm{O}_{2}$ pretreatment to eliminate organic matter and clay deflocculation using sodium hexametaphosphate and mechanical agitation (Gee and Bauder, 1986). When the last volume of water had infiltrated, a small sample was collected within the ring to determined the field saturated gravimetric water content. Both initial and field saturated gravimetric water content values were converted into volumetric ones, i.e. $\theta_{0}$ and $\theta_{f s}$, by the dry soil bulk density, $\rho_{b}\left(\mathrm{Mg} \mathrm{m}^{-3}\right)$, measured on an undisturbed soil core ( $0.05 \mathrm{~m}$ in height by $0.05 \mathrm{~m}$ in diameter) collected in the subsoil in close vicinity of the infiltrometer ring.

\section{Results and discussion}

In site 1 , the steady state infiltration rate, $q_{c}$, through the surface crust ranged from a minimum value of 390 to a maximum value of 755 $\mathrm{mm} \mathrm{h}^{-1}$ with a mean value of $561 \mathrm{~mm} \mathrm{~h}^{-1}$ (Table 1) In site $2, q_{c}$ ranged from 117 to $200 \mathrm{~mm} \mathrm{~h}^{-1}$ (average $147 \mathrm{~mm} \mathrm{~h}^{-1}$ ). As expected, a lower $q_{c}$ values were observed in the clay soil where the relatively weaker structure of the soil aggregates lead to the formation of a more compact surface crust (Figure 1). The coefficient of variation of $q_{c}$ in the two soils were similar, even if the hydrodinamic characteristics of the surface crust could be considered more homogeneous in the clay soil (CV = $23 \%)$ than in the sandy loam soil (CV = 19\%) at the time of field tests.

The hydraulic properties, i.e. the water retention curve and the hydraulic conductivity function, of the soil underneath the crust showed similarities between the two soils. The relationships $\theta(h)$ were more variable with the considered run in the sandy loam soil than in the clay soil. The opposite result was found for the hydraulic conductivity functions (Figure 2). The shape parameters ( $n, m$ and $\eta$ ), that basically depend on the PSD, were characterized by small coefficients of variation ( $\mathrm{CV}<2.5 \%)$ for both soils. For the sandy loam soil, the average values of $n, m$ and $\eta(N=11)$, were $2.15,0.07$ and 16.0. For the clay soils $(N=15), n=2.07, m=0.03$ and $=31.4$. These results did not coincide with the mean values listed by Minasny and McBratney (2007) for the USDA textural categories, which is obvious given the differences in terms of both origin and sample size of the datasets. However, the shape parameters of this investigation were relatively close to the ones reported by the cited Authors and also in line with the circumstance that a lower $n$ and a higher value should be expected for a clay soil than a sandy loam soil.

The mean values of $\theta_{f s}$ were $0.62 \mathrm{~cm}^{3} \mathrm{~cm}^{-3}(\mathrm{CV}=5.0 \%)$ in site 1 and $0.56 \mathrm{~cm}^{3} \mathrm{~cm}^{-3}(\mathrm{CV}=5.8 \%)$ in site 2 . Actually, estimations of total porosity conducted from independently measured soil bulk densities by assuming a particle density of $2.65 \mathrm{~kg} \mathrm{~m}^{-3}$, yielded similar results, i.e. a mean value of $0.59 \mathrm{~cm}^{3} \mathrm{~cm}^{-3}$ for the sandy loam of site 1 and $0.55 \mathrm{~cm}^{3} \mathrm{~cm}^{-}$ ${ }^{3}$ for the clay soil (site 2 ). The pressure head scale parameter, $h_{g}$, and the field saturated hydraulic conductivity, $K_{f s}$, that mainly depend on the infiltration experiments, were characterized by a greater variability. The mean values of the two scale parameters were $h_{g}=87 \mathrm{~mm}$ (CV $=61 \%)$ and $K_{f s}=346 \mathrm{~mm} \mathrm{~h}^{-1}(\mathrm{CV}=44 \%)$ for site 1 , and $h_{g}=241 \mathrm{~mm}$ $(\mathrm{CV}=118 \%)$ and $K_{f s}=731 \mathrm{~mm} \mathrm{~h}^{-1}(\mathrm{CV}=87 \%)$ for site 2 . The estimated values of $h_{g}$ are in agreement with the texture of the two soils given that a higher absolute value of the pressure scale parameter is expected in fine soils exhibiting a smaller modal pore size (Haverkamp et al.,

Table 1. Statistics of the hydraulic parameters of the van GenuchtenBroooks and Corey model $\left(\mathbf{n}, \mathbf{m}, \eta, \theta_{f s}\right.$, hg and $\left.\mathbf{K}_{f s}\right)$ for the subsoil and steady state infiltration rate through the surface crust $\left(q_{c}\right)$.

\begin{tabular}{|c|c|c|c|c|c|c|c|}
\hline & $n$ & $m$ & $\eta$ & $\begin{array}{c}\theta_{f s} \\
\left(\mathrm{~m}^{3} \mathrm{~m}^{-3}\right)\end{array}$ & $\begin{array}{c}h_{g} \\
(\mathrm{~mm})\end{array}$ & $\begin{array}{c}\boldsymbol{K}_{f s} \\
\left(\mathrm{~mm} \mathrm{~h}^{-1}\right)\end{array}$ & $\begin{array}{c}q_{c} \\
\left(\mathrm{~mm} \mathrm{~h}^{-1}\right)\end{array}$ \\
\hline \multicolumn{8}{|c|}{ Site 1 sandy loam $N=11$} \\
\hline $\min$ & 2.149 & 0.069 & 15.6 & 0.576 & -180 & 193 & 390 \\
\hline $\max$ & 2.159 & 0.074 & 16.4 & 0.649 & -26 & 623 & 755 \\
\hline mean & 2.154 & 0.071 & 16.0 & 0.615 & -87 & 346 & 561 \\
\hline CV (\%) & 0.2 & 2.5 & 2.2 & 5.0 & 61.0 & 43.5 & 23.2 \\
\hline \multicolumn{8}{|c|}{ Site 2 clay $N=15$} \\
\hline $\min$ & 2.067 & 0.032 & 30.5 & 0.514 & -886 & 14 & 117 \\
\hline $\max$ & 2.073 & 0.035 & 33.0 & 0.622 & -51 & 1777 & 200 \\
\hline mean & 2.070 & 0.034 & 31.4 & 0.557 & -241 & 731 & 147 \\
\hline CV (\%) & 0.1 & 2.4 & 2.3 & 5.8 & 118.0 & 86.6 & 18.7 \\
\hline
\end{tabular}
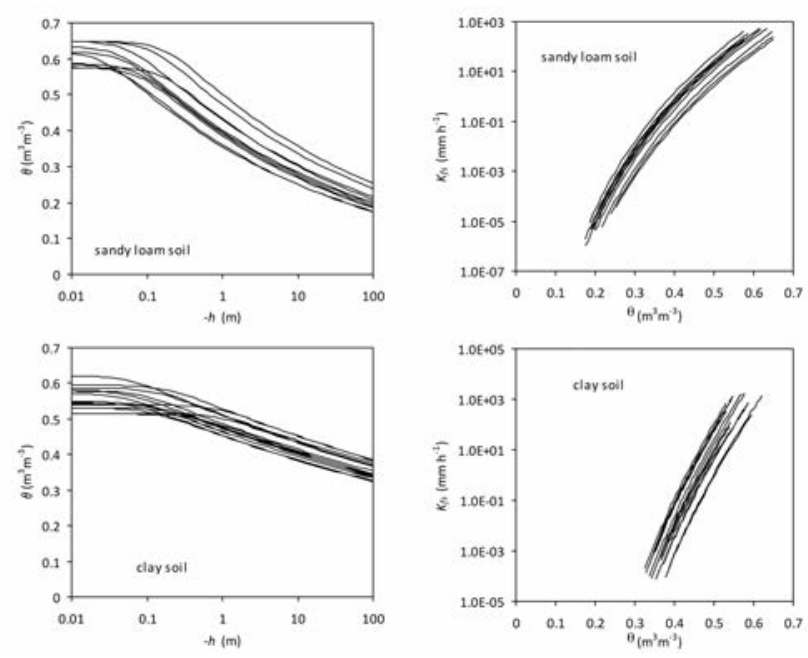

Figure 2. Water retention curves and hydraulic conductivity functions for the subsoil of site 1 ( $a$ and $b$ ) and site 2 ( $c$ and d). 
2006). A higher mean $K_{f s}$ value in the clay soil probably occurred because soils rich in clay often show macropores, microcraks and other structural discontinuities that help water transmission (Bagarello et $a l ., 2010)$. In this case, the variability of the measured $K_{f s}$ also increases depending on whether the macropores are sampled or not (Bagarello et $a l, 2012)$. In fact, the $K_{f s}$ values measured by the BEST procedure in the clay soil extended over two orders of magnitude from a minimum of 14 $\mathrm{mm} \mathrm{h}^{-1}$ to a maximum of $1777 \mathrm{~mm} \mathrm{~h}^{-1}$ whereas in the sandy loam soil the field saturated hydraulic conductivity values differed, at the most, by a factor of 3.2 .

In site 1, the ratio of the steady state flow rate though the crust to the field saturated hydarulic conductivity of the subsoil, $q_{d} K_{f s}$, was greater than one in 10 out of 11 experiments (mean value, $q_{d} K_{f s}=1.56$ ) and also for the only experiment in which $q_{\mathrm{c}}<K_{f s}$, the ratio $q_{d} K_{f_{s}}$ was very close to one $\left(q_{d} / K_{f s}=0.93\right)$. It was concluded that the visually observed surface crust was not hydraulically effective in reducing infiltration in this soil. Surface soil crust in the sandy loam site was thinner $\left(L_{c}=2\right.$ $3 \mathrm{~mm}$ ) and less developed than in the clay soil. As can be seen in Figure 3 , it includes many sand particles that avoided excessive compaction of the surface layer. According to Valentin and Bresson (1992), in cultivated soils of loamy type slaking crusts develop as a result of aggregate breakdown probably induced by entrapped air compression when the soil is dry before rainfall. Such crusts are thin (1-3 mm), rather porous with a no clear textural separation between coarse and fine particles and the infiltration rate is relatively high (De Jong et al., 2011). Another factor that lead to the formation of a slaking crust in the sandy loam soil of site 1, could be the protective effect of the tree canopy that prevented the soil surface from the direct impact of the drops. Therefore, the main mechanism for disaggregation was the wetting of the dry aggregate rather than the kinetic energy of the rainfall.

In the clay soil, the condition $q_{d} K_{f s}<1$ was observed in 10 experiments out of 15 experiments denoting an increased hydraulic resistance of the surface crust. With the exclusion of one experiment that yielded a value of $q_{d} / K_{f s}=9.1$, mainly as a consequence of an extremely low value on the subsoil field saturated hydraulic conductivity $\left(K_{f s}=14\right.$ $\mathrm{mm} \mathrm{h}^{-1}$ ), the $q_{d} / K_{f s}$ values ranged from 0.09 to 1.59 with a mean value of $0.49(\mathrm{CV}=108 \%)$. Therefore, the formation of a surface crust acted as a barrier to water infiltration in the clay soil. The crust in clay soil was thicker $\left(L_{c}=5-7 \mathrm{~mm}\right)$ and probably more compact than in the sandy loam soil (Figure 4). Physical characterization of the soil crust should
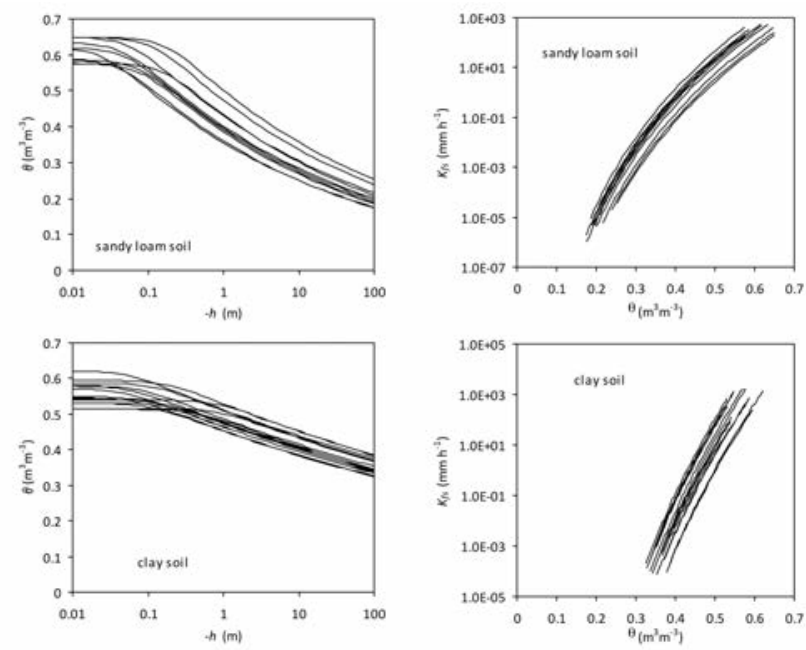

Figure 2. Water retention curves and hydraulic conductivity functions for the subsoil of site 1 ( $a$ and $b$ ) and site 2 ( $c$ and d). be carried out in additional testing of the proposed field method. However, visual inspection of the removed crust showed a distinct structural separation between the compacted surface layer and underlying undisturbed subsoil that, according to Valentin and Bresson (1992), typical occurs in the coalescing crust. Such crusts results mainly from gradual compaction due to aggregate coalescence by deformation under plastic conditions. This crusting process is observed in wet soils under heavy rainfall intensity.

For the experiments in which $q_{d} K_{f s}<1(N=10)$, the pressure head at the soil-crust interface, $h_{s}$, varied between 263 and $77 \mathrm{~mm}$ with a mean value of $180 \mathrm{~mm}(\mathrm{CV}=35.5 \%)$ (Table 2$)$. Considering that water is supplied at the surface of the crust with a pressure head close to zero ( $h_{0} \approx 5 \mathrm{~mm}$ ) this result shows what marked reduction of the water pressure head occurs in the first $\mathrm{mm}$ of the profile due to the hydraulic resistance of the crust. If the thickness of the crust is neglected, the hydraulic resistance calculated from eq. (5) ranged from 0.39 to $2.24 \mathrm{~h}$ with a mean value of $1.31 \mathrm{~h}(78 \mathrm{~min})$. The corresponding mean value

Table 2. Statistics of the pressure head at the crust-subsoil interface, $\boldsymbol{h}_{\boldsymbol{s}}$, crust thickness, $L_{c}$, hydraulic resistance, $\boldsymbol{R}_{c}$ and hydraulic conductivity, $\boldsymbol{K}_{c}$, of the surface crust of the clay soil determined for the experiments in which $q_{d} / K_{f_{s}}<1(\mathrm{~N}=10)$.

\begin{tabular}{|c|c|c|c|c|c|c|c|}
\hline Statistic & $q d K_{f s}$ & $\begin{array}{c}h_{s} \\
(\mathrm{~mm})\end{array}$ & $\begin{array}{c}L_{c} \\
(\mathrm{~mm})\end{array}$ & $\begin{array}{c}\boldsymbol{R}_{c} \\
\text { (h) } \\
\text { eq. }\end{array}$ & $\begin{array}{c}K_{c} \\
\left(\mathrm{~mm} \mathrm{~h}^{-1}\right)\end{array}$ & $\begin{array}{l}\boldsymbol{R}_{c} \\
\text { (h) } \\
\text { eq. }\end{array}$ & $\begin{array}{c}K_{c} \\
\left(\mathrm{~mm} \mathrm{~h}^{-1}\right) \\
(6)\end{array}$ \\
\hline $\min$ & 0.09 & -263 & 5 & 0.385 & 2.68 & 0.41 & 2.62 \\
\hline $\max$ & 0.84 & -77 & 7 & 2.241 & 12.97 & 2.29 & 12.18 \\
\hline mean & 0.24 & -180 & 6 & 1.312 & 5.77 & 1.35 & 5.53 \\
\hline CV (\%) & 97.6 & 35.5 & 11.1 & 47.8 & 53.5 & 47.0 & 51.9 \\
\hline
\end{tabular}

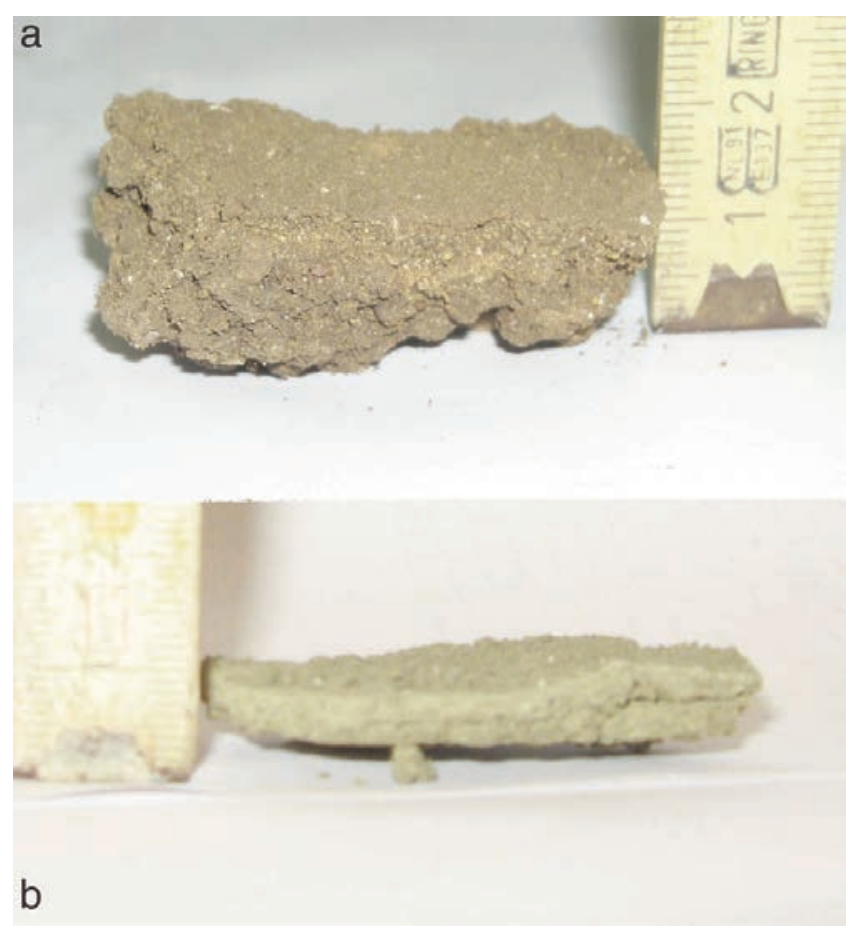

Figure 3. Slaking structural crust on the sandy loam soil of site 1 (a) and coalescing crust on the clay soil of site 2 (b). 
of the hydraulic conductivity of the crust was $5.8 \mathrm{~mm} \mathrm{~h}^{-1}$. Considering the thickness of the crust (6) the mean value of the crust hydraulic resistance was $1.35 \mathrm{~h}$ (81 min), with a mean value of the hydraulic conductivity of $5.5 \mathrm{~mm} \mathrm{~h}^{-1}$. Therefore, calculation of the hydraulic parameters of the crust were not appreciably affected by $L_{c}$. A practical implication of this result is that measuring the crust thickness is not strictly necessary to calculate its conductivity and hydraulic resistance.

\section{Conclusions}

Soil surface crusting may severely affect agricultural soils as it significantly reduces infiltration, hampers germination of seeds and reduces root aeration and water availability. Knowledge of the hydrodinamic properties of the surface soil crust is important to predict and mitigate its negative effects. A simplified method to determine the hydraulic resistance of the surface crust is presented that is based on the approach by Hillel and Gardner (1969). It requires the knowledge of the steady state infiltration rate in the crusted soil and the hydraulic properties of the soil underlying the crust and combines two in situ infiltrometric experiments. A mini-disk tension infiltrometer is first conducted at the soil surface to measure the steady-state infiltration rate. Then, the surface crust is removed, its thickness is measured, and a ponded infiltration test is performed at the same site to determine the hydraulic properties of the underlying soil by the Beerkan Estimation of Soil Transfer parameters (BEST) procedure.

The method was tested in a sandy loam and a clay soil after a prolonged rainfall period that allowed the formation a surface crust. In the sandy loam soil, a 2-3 mm thick slaking crust was visually observed, but ratio of the steady state flow rate to the field saturated hydarulic conductivity of the subsoil, $q_{d} / K_{f}$, was greater than one in 10 out of 11 experiments thus detecting no increase of the surface hydraulic resistance. In the clay soil, a 5-7 mm thick crust was formed that was attributed to gradual coalescence of the plastic, wet aggregates by rainfall compaction. In this soil, the condition $q_{d} / K_{f s}<1$ was observed in 10 out of 15 experiments denoting an increased hydraulic resistance of the surface crust. The hydraulic resistance was not appreciably affected by the crust thickness. The mean value of the crust hydraulic resistance was $1.31-1.35 \mathrm{~h}$ (78-81 min), with a mean value of the hydraulic conductivity of $5.5-5.8 \mathrm{~mm} \mathrm{~h}^{-1}$. The developed method is particularly simple and appears to be suitable to discriminate between different levels of the hydraulic resistance of the surface crust. However, further investigations involving different soil and crust types is necessary in order to confirm its reliability.

\section{References}

Assouline S. 2004. Rainfall-induced soil surface sealing: a critical review of observations, conceptual models, and solutions. Vadose Zone Journal, 3:570-591.

Bagarello V., Di Stefano C., Ferro V., Iovino M., Sgroi A., 2010. Physical and hydraulic characterization of a clay soil at the plot scale. Journal of Hydrology, 387: 54-64.

Bagarello V, D’Asaro F, Iovino M. 2012. A field assessment of the Simplified Falling Head technique to measure the saturated soil hydraulic conductivity. Geoderma 187-188: 49-58.

Bresson L.-M., Boiffin J. 1990. Morphological characterization of soil crust development stages on an experimental field. Geoderma, 47:301-325.

Brooks R.H., Corey C.T. 1964. Hydraulic properties of porous media. Hydrol. Paper 3, Colorado State University, Fort Collins.
Burdine N.T. 1953. Relative permeability calculation from pore size distribution data. Petr. Trans. Am. Inst. Min. Metall. Eng., 198:71-77.

De Jong S.M., Addink E.A., van Beek L.P.H., Duijsings D. 2011. Physical characterization, spectral rensponse and remotely sensed mapping of Mediterranean soil surface crusts. Catena, 86:24-35.

Dohnal, M., Dusek, J., Vogel, T., 2010. Improving hydraulic conductivity estimates from minidisk infiltrometer measurements for soils with wide pore-size distributions. Soil Sci. Soc. Am. J. 74(3), 804-811.

Gee G.W., Bauder J.W. 1986. Particle-size analysis. In Methods of soil analysis. Part 1, Klute A (ed), 2nd ed, ASA and SSSA, Madison, WI, USA, 383-411.

Haverkamp R., Debionne S., Vialet P., Angulo-Jaramillo R., de Condappa D. 2006. Soil properties and moisture movement in the unsaturated zone. In J.W. Delleur (ed.), The handbook of groundwater engineering, CRC, Boca Raton, FL.

Haverkamp R. Ross P.J., Smettem K.R.J., Parlange J.Y. 1994. Threedimensional analysis of infiltration from the disc infiltrometer. 2. Physically based infiltration equation. Water Resources Research, 30:2931-2935.

Hillel D., Gardner W.R. 1969. Steady infiltration into crust-topped profiles. Soil Science, 180(2):137-142.

Lassabatère L., Angulo-Jaramillo R., Goutaland D., Letellier L., Gaudet J.P., Winiarski T., Delolme C. 2010.. Effect of settlement of sediments on water infiltration in two urban infiltration basins. Geoderma, 156:316-325.

Lassabatère, L., Angulo-Jaramillo, R., Soria Ugalde, J.M., Cuenca, R., Braud, I., Haverkamp, R., 2006. Beerkan estimation of soil transfer parameters through infiltration experiments - BEST. Soil Science Society of America Journal 70, 521-532.

Li X.-Y., González A., Solé-Benet A. 2005. Laboratory methods for the estimation of infiltration rate of soil crusts in the Tabernas Desert badlands. Catena, 60:255-266.

Lichner L., Hallett P.D., Feeney D.S., Ďugová 0. Šír M., Tesař M. 1997. Field measurement of soil water repellency and its impact on water flow under different vegetation. Biologia, 62(5):537-541.

Madsen M.D., Chandler D.G. 2007. Automation and use of Mini Disk Infiltrometer. Soil Science Society of America Journal, 71:1469 1472.

Minasny B., McBratney A.B. 2007. Estimating the water retention shape parameter from sand and clay content. Soil Science Society of America Journal, 71:1105-1110.

Reynolds W.D. 2006: Tension infiltrometer measurements: implication of pressure head offset due to contact sand. Vadose Zone Journal, 5:1287-1292.

Šimůnek J., Angulo-Jaramillo R., Schaap M.G., Vandervaere J.P., van Genuchten M.T. 1998. Using an inverse method to estimate the hydraulic properties of crusted soils from tension disc infiltrometer data. Geoderma, 86:61-81.

Šimůnek J., van Genuchten M.Th. 1997. Estimating unsaturated soil hydraulic proper-ties from multiple tension disc infiltrometer data. Soil Science, 162(6):383-398.

Touma J., Raclot D., Al-Ali Y., Zante P., Hamrouni H., Dridi B. 2011. In situ determination of the soil surface crust resistance. Journal of Hydrology, 403:253-260.

Valentin C., Bresson L.-M. 1992. Morphology, genesis and classification of surface crusts in loamy and sandy soils. Geoderma, 55:225-245.

van Genuchten M.Th. 1980. A closed form equation for predicting the hydraulic conductivity of unsaturated soils. Soil Science Society of America Journal, 44:892-898.

Vandervaere J.P., Peugeot C., Vauclin M., Angulo-Jaramillo R., Lebel T. 1997. Estimating hydraulic conductivity of crusted soils using disc infiltrometers and minitensiometers. Journal of Hydrology, 188189:209-223. 